\title{
The Establishment and Application of Mobile Electronic Surveillance System for Infectious Diseases with the Help of China - Sierra Leone, 2016-Present
}

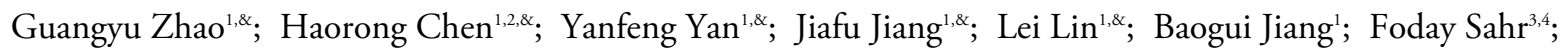 \\ Stephen Sevalie ${ }^{4}$; Qiang Xu' ${ }^{1}$ Jinjin Chen ${ }^{1}$; Henry Saidu Bangura ${ }^{4}$; Kandeh Bassie Kargbo \\ Yajun Song ${ }^{1, *} ;$ Wei Liu ${ }^{1, *}$; Liqun Fang ${ }^{1, * ;}$; Yansong Sun ${ }^{1,2, *}$
}

\begin{abstract}
Introduction: Infectious disease surveillance has long been a challenge for low-income countries like Sierra Leone. Traditional approaches based on paper and Short Message Service (SMS) were subject to severe delays in obtaining, transmitting, and analyzing information.

Methods: During the China aid operation for fighting Ebola since the end of 2014, a mobile electronic surveillance system for infectious diseases (MESSID) was developed in collaboration with the Republic of Sierra Leone Armed Forces (RSLAF), which comprised an Android-based reporting system and a complementary web-based program designed by Active Server Page.NET (ASP.NET) with the main functions including surveillance, real-time reporting, and risk assessment of infectious diseases.

Results: MESSID was successfully registered in June 2016 and had been used by all medical and health institutions in RSLAF. From June 1, 2016 to July 5, 2021, 34,419 cases were diagnosed with 47 infectious diseases of 5 categories, with a total of 42 clinical symptoms. Compared to traditional approaches based on paper and SMS, the MESSID showed flexibility, high efficiency, convenience, and acceptability.

Discussion: MESSID is an accessible tool for surveillance of infectious diseases in Sierra Leone and possibly in other African countries with similar needs, capable of improving timeliness of disease reporting, thus rendering a timely outbreak detection and response.
\end{abstract}

\section{INTRODUCTION}

Fundamental disease surveillance systems are essential to guide the informed prevention and control of infectious diseases for each country (1-2), However, low and middle-income countries are more readily afflicted by emerging infectious diseases while lacking such surveillance systems combined with the resources needed for pathogen surveillance (3). During 2014-2015, an outbreak of Ebola virus disease (EVD) swept across parts of West Africa with high incidence and case fatality reported in Sierra Leone. A lack of public health infrastructure in conjunction with delays in laboratory detection and implementation of control interventions have contributed to the widespread transmission of EVD in the country. Major gaps exist for collecting, processing, and transmitting data, primarily due to the lack of adequate reporting tools and limited access to laboratory diagnosis of infectious diseases. The paper and SMS disease reporting systems had been applied by the medical and healthcare system of Republic of Sierra Leone Armed Forces (RSLAF). However, the submission of surveillance forms was affected by poor transport and telecommunication infrastructures, poor electricity facilities, weather conditions, and challenging terrain.

In September 2014, the China Mobile Laboratory Testing Team was dispatched at the request of the Sierra Leone government to support Sierra Leone and to respond to the World Health Organization's (WHO) and the United Nations' (UN) requests to help control the EVD epidemic (4). During this aid operation, Chinese aid experts have designed and implemented a mobile electronic surveillance system for infectious diseases (MESSID) via collaboration with the RSLAF. This article described the design and implementation of the system, presented preliminary data obtained since June 2016, and provided examples of data that are being obtained in Sierra Leone.

\section{METHODS}

\section{System Structure}

The development of MESSID system was primarily 
based on a display center, a service center, a data center, and user authority. A schematic overview of the MESSID is shown in Figure 1.

Display center: MESSID used a web-based graphical interactive interface with C\# (version 4.0; Microsoft Corporation; Washington State, U.S.) as the main development programming language, and Visual Studio 2012 (version 2012; Microsoft Corporation; Washington State, U.S.) as the programming IDE (Integrated Development Environment). Microsoft.NET Framework (version 4.0; Microsoft Corporation; Washington State, U.S.) was adopted as the main development framework to build applications with pleasant user experience, seamless communication across technical boundaries, and support for various business types. Model View Controller was adopted for design specifications to map traditional input, processing, and output functions in a logical graphical user interface structure.

Service center: To attain effective data sharing and interaction and statistical analysis, Sever/Brower architecture was adopted, and handheld terminal data collection was using the Android platform and using the Java programming language (version 11; Oracle; California, U.S.). Under this structure, the user interface was implemented through the web browser, and transaction logic was implemented in the front end
(Browser), while the main transaction logic is implemented on the server side (Server), forming the so-called three-tier structure. This greatly simplifies the client-computer load, reducing the cost and workload of system maintenance, upgrades, and the overall cost to end users.

Data center: In order to realize data sharing and interactions between various systems, Microsoft's enterprise-level relational database SQL Server (version 2008 R2; Microsoft Corporation; Washington State, U.S.) was used as the database storage system to build a unified data center to ensure consistency and timeliness of the data collection.

User authority: An extended Role-Based Access Control permission control model was adopted, which combined user permissions and role permissions. In user permissions, users were assigned permissions. During emergencies, there was no need to modify the content of role permissions.

\section{Data Collection and Reporting}

Two kinds of questionnaires (symptom surveillance and laboratory data) were designed to collect data from each case, which included date, demography, epidemiological information, clinical syndrome, clinical diagnosis, laboratory testing if applicable, etc.

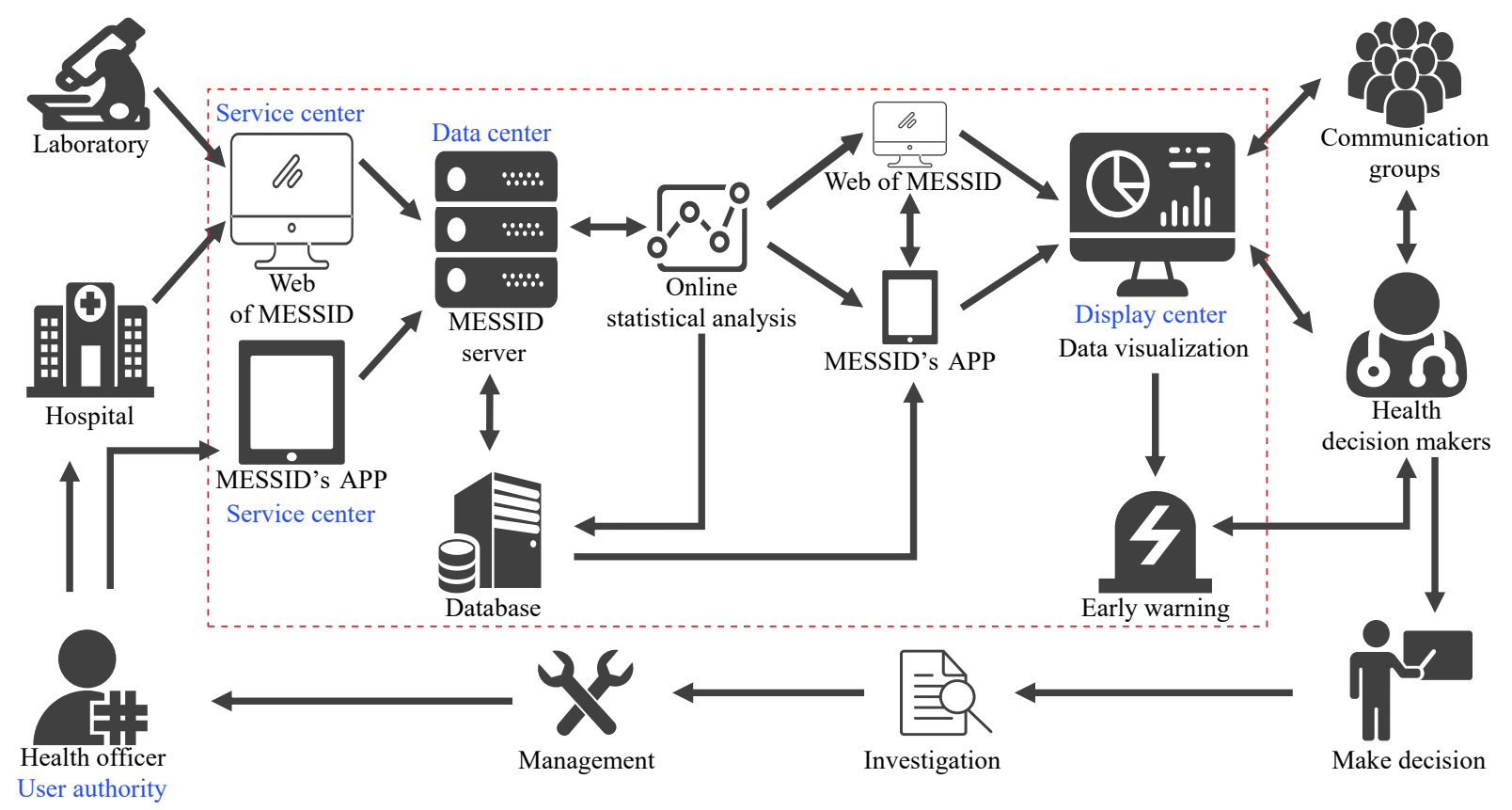

FIGURE 1. A schematic overview of the MESSID.

Note: The display center was used to visualize data, maps, or analyzed results to users; the service center was used for data filling, data transmission and sharing, and data exporting; the data center was used for data storage and management; and user authority was used to assign permissions to users.

Abbreviation: MESSID=mobile electronic surveillance system for infectious diseases. 
The location of each survey was also collected with global positioning system, and latitudinal and longitudinal information was integrated into the report data. For data transmission, in addition to reporting through the browser version of the MESSID, a MESSID APP was designed to facilitate the staff to report cases through the mobile terminal. As shown in Table 1, MESSID's APP had most of the functions of the MESSID, except that no data downloading was permitted (Figure 2A-B). Moreover, the intelligent report was used in MESSID APP to improve the efficiency of reporting. At locations covered by mobile telecommunication network, collected data could be submitted real time to the data center at the 34 Military Hospital through the wireless network service of tablet or mobile phone. Under situations when the surveys were performed in remote areas without cellular service, the data would be stored locally, and the MESSID APP would automatically upload the data when the user returned to an area with a mobile telecommunication network.

\section{Data Management and Visualization}

There was also pre-stored baseline information in the MESSID for the user's reference, primarily involving the local socioeconomic, geographic, and environmental data at the provincial level. Based on this information, the frequency of cases and their diagnosis and the collected symptom information could be summarized in relation to age, gender, occupation, time duration, region, sentinel clinics, etc.
(Figure 2D). The results could also be exported as an Excel file for further analysis. The spatiotemporal distribution of symptoms, cases, and diagnoses could be summarized and presented by generating spatial distribution maps, epidemic curves, and dynamic statistical graphs by gender, age, and occupation (Figure 2C). Thus, the disease situation could be assessed by health officers and could be customizable to aid the generation of epidemic situation reports in regular (weekly, monthly, and yearly) or irregular (customizable time, region, population, and selected elements) intervals. During data collection and processing, privacy and data security were considered; no personal identifiers were linked to survey submissions and all data were denominated for analysis.

\section{RESULTS}

\section{The Application of MESSID}

A pilot version of this system was implemented in June 2016 in partnership with all medical and health institutions in RSLAF. The systems were successfully registered and used by medical staff from Joint Medical Units of RSLAF stationed at the 12 districts, which had taken all 31 Medical Inspection Rooms and hospitals in RSLAF.

During the operation period from June 1, 2016 to July 5, 2021 in Sierra Leone, a total of 34,419 cases were diagnosed with 47 infectious diseases, with a total of 42 clinical symptoms. The median age of the

TABLE 1. The functions of MESSID and MESSID APP in comparison with traditional approaches of disease reports based on paper and SMS.

\begin{tabular}{|c|c|c|c|}
\hline Function & $\begin{array}{l}\text { Traditional approach } \\
\text { based on paper and SMS } \\
\text { paper and SMS reporting }\end{array}$ & MESSID APP & MESSID \\
\hline Data collection & Manually collect data & Collect data based on the mobile terminals & $\begin{array}{l}\text { Collect data based on the website on users' } \\
\text { computers }\end{array}$ \\
\hline Data storage & Manually enter data & $\begin{array}{l}\text { Data was locally stored and automatically uploaded } \\
\text { to the data center when the mobile } \\
\text { telecommunication network was available }\end{array}$ & $\begin{array}{l}\text { Automatically uploaded the data to the data } \\
\text { center }\end{array}$ \\
\hline $\begin{array}{l}\text { Data } \\
\text { transmission }\end{array}$ & $\begin{array}{l}\text { By paper or SMS report } \\
\text { delivery }\end{array}$ & $\begin{array}{l}\text { Automatically data transmission through wireless } \\
\text { network service of tablet or mobile phone }\end{array}$ & $\begin{array}{l}\text { Data transmission through network service } \\
\text { of users' computers }\end{array}$ \\
\hline Data content & $\begin{array}{l}\text { Disease species and the } \\
\text { number of cases }\end{array}$ & $\begin{array}{l}\text { Demographical, spatiotemporal, clinical, } \\
\text { epidemiological, and therapeutic information of } \\
\text { patients, as well as laboratory testing information if } \\
\text { applicable }\end{array}$ & $\begin{array}{l}\text { Demographical, spatiotemporal, clinical, } \\
\text { epidemiological, therapeutic information, } \\
\text { and laboratory testing information if } \\
\text { applicable }\end{array}$ \\
\hline $\begin{array}{l}\text { Real-time } \\
\text { statistical } \\
\text { analysis }\end{array}$ & $\begin{array}{l}\text { Unable to conduct real- } \\
\text { time statistical analysis }\end{array}$ & Query data with simple statistical analysis & $\begin{array}{l}\text { Real-time online statistical analysis on the } \\
\text { website in client computers }\end{array}$ \\
\hline $\begin{array}{l}\text { Data } \\
\text { visualization }\end{array}$ & $\begin{array}{l}\text { Data visualization requires } \\
\text { additional software }\end{array}$ & Part of the data could be visualized on the app & $\begin{array}{l}\text { The data could be visualized on the website } \\
\text { in client computers }\end{array}$ \\
\hline $\begin{array}{l}\text { Real-time risk } \\
\text { assessment } \\
\text { and early } \\
\text { warning }\end{array}$ & $\begin{array}{l}\text { Difficulty for risk } \\
\text { assessment and early } \\
\text { warning in time }\end{array}$ & $\begin{array}{l}\text { Real-time surveillance and easy risk assessment } \\
\text { through the app }\end{array}$ & $\begin{array}{l}\text { The global situation analysis, real-time } \\
\text { surveillance and be easy for risk } \\
\text { assessment and early warning by health } \\
\text { officials }\end{array}$ \\
\hline
\end{tabular}

Abbreviations: MESSID=mobile electronic surveillance system for infectious diseases; SMS=short message service. 
A

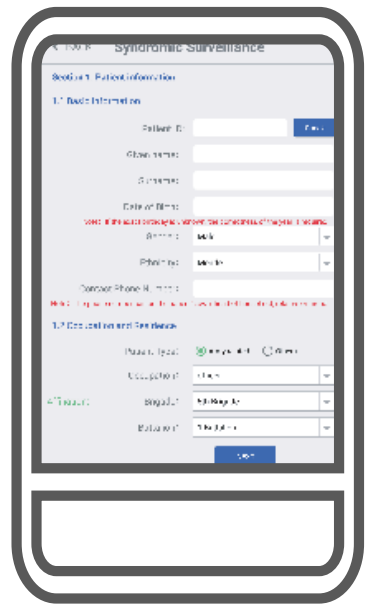

B

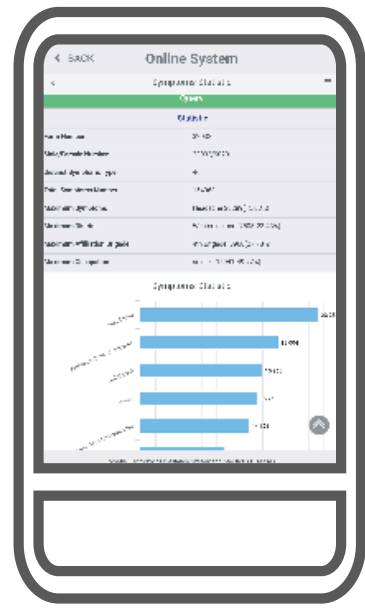

C
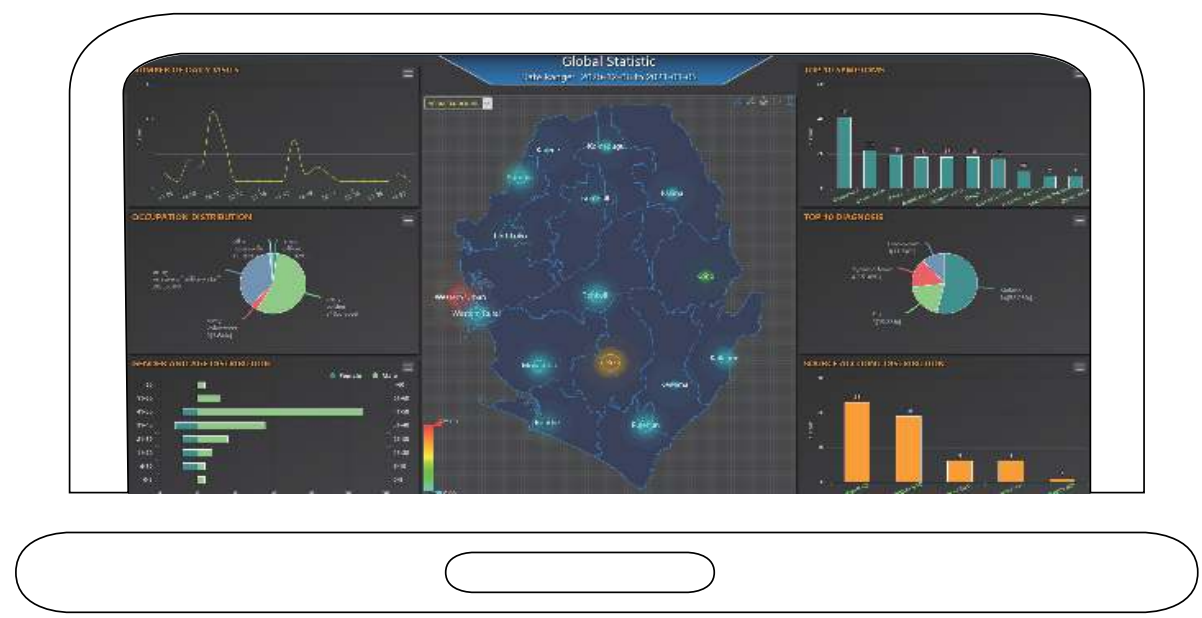

D
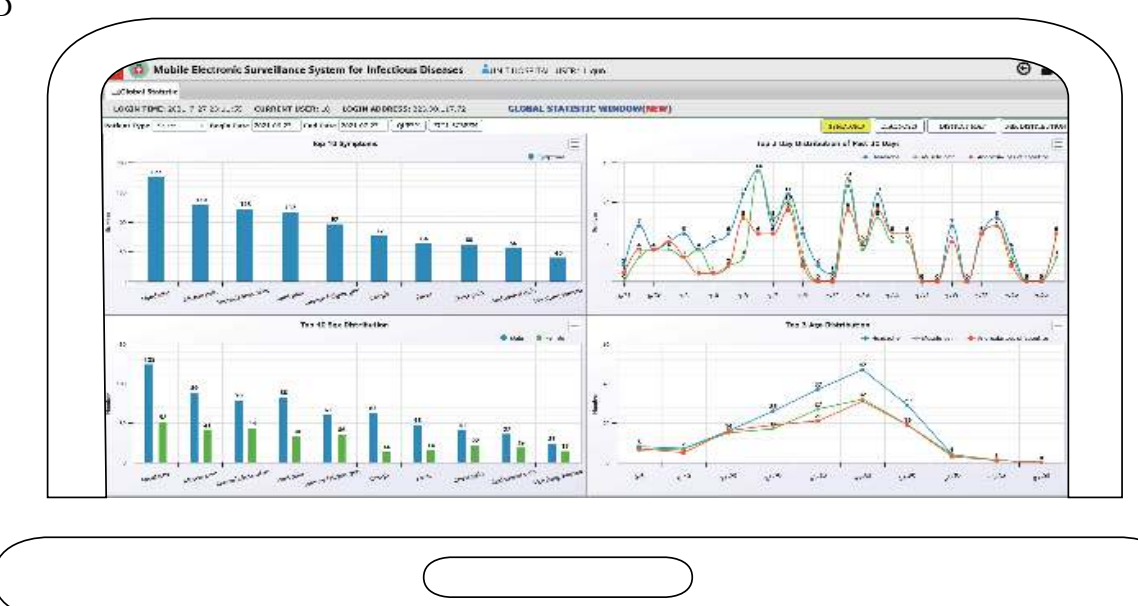

FIGURE 2. Interface display of MESSID APP in tablet and MESSID in PC. (A) Interface of questionnaire form for data collection in the MESSID APP; (B) Interface of online statistic in MESSID APP; (C) Interface of global situation analysis on the website of MEESID (http://www.messid.net/userinterface/Login.aspx); (D) The interface of symptom statistics on the website of MESSID.

Abbreviation: MESSID=mobile electronic surveillance system for infectious diseases.

patients were 41 years old (range: $0-118$ ) and $71.90 \%$ males. Geographically, cases were predominantly reported from Western Area Urban District $(9,013$ records, 26.19\%) and Bombali District (6,922 records, 
$20.11 \%$ ). A total of 37,954 clinical diagnoses were submitted, which were related to 47 diseases or their coinfections. The most common diagnosis was malaria $(15,647$ cases, $45.46 \%)$, followed by flu (3,691 cases, $10.72 \%)$, typhoid fever $(2,794$ cases, $8.12 \%)$, mycobacteriosis (304 cases, $0.88 \%$ ). Each syndromic grouping was linked to ways of disease transmission, including vector-borne diseases, zoonotic diseases, respiratory infections diseases, enteric infectious diseases, and blood, sexually, and direct contact transmitted diseases.

Life threatening and severe infections or emerging infectious diseases were alerted and responded to in a timely manner, including yellow fever (10 cases), Rift Valley fever (1 case), anthrax (1 case) and melioidosis (1 case). Notably, the early alert for COVID-19 was identified through MESSID. During the early stages of COVID-19 epidemic in Africa, the reported COVID-19 cases in Sierra Leone totaled at 50 cases as of April 22, 2020 (5), out of which 24 cases received by the military medical and health institutions were recorded by MESSID, which had taken an important part of overall cases in the early days of COVID-19 epidemic in the country. The first COVID-19 patient recorded by MESSID was reported on March 31, 2020, which was 1 day earlier than the official report from WHO (on April 1, 2020).

\section{Comparison Between MESSID and Traditional Approach Based on Paper and SMS}

MESSID had particular benefits of convenience, flexibility, high efficiency, and acceptability, compared to traditional approaches based on paper and SMS (Table 2) (6). The MESSID reporting process was simple and highly efficient, taking only a few minutes to successfully report a case, in contrast with 3-5 days taken for traditional approach based on paper and SMS. A high receptive attitude to the MESSID was obtained from the health workers. A high flexibility of MESSID allows for the update of information collection and organization. For example, COVID-19 was added to the surveillance system when the WHO declared that the COVID-19 outbreak constituted a Public Health Emergency of International Concern (7). The real-time data collection, analysis, and report generation had allowed an early detection of change of infectious diseases.

\section{DISCUSSION}

The currently described MESSID offered an integrated solution that comprised surveillance, realtime reporting, and risk assessment, therefore enhancing the approach for authorities to collect baseline data for common infectious diseases or emerging infectious diseases (Table 2). Informed preventive measures could be taken if necessary. The platform could also assist the healthcare sector in planning and control measures such vaccine deployment.

In recent years, various countries and organizations have established electronic surveillance systems of infectious diseases or public health events such as

TABLE 2. Performance and characteristics of MESSID by compared with traditional approach of disease reports based on paper and SMS.

\begin{tabular}{|c|c|c|}
\hline Features & Traditional approach based on paper and SMS & MESSID \\
\hline Convenience & $\begin{array}{l}\text { 1. The reporting process is complicated and tedious. } \\
\text { 2. Not able to report immediately. }\end{array}$ & $\begin{array}{l}\text { 1. The reporting process is clear and simple. } \\
\text { 2. Able to report immediately. }\end{array}$ \\
\hline Flexibility & $\begin{array}{l}\text { 1. Due to the tedious reporting process, it takes a long } \\
\text { time for health workers to fully grasp the reporting } \\
\text { process. } \\
\text { 2. Traditional approach based on paper and SMS } \\
\text { cannot adapt to changing information needs. } \\
\text { 3. Traditional approach based on paper and SMS } \\
\text { cannot flexibly change the content of the questionnaire. }\end{array}$ & $\begin{array}{l}\text { 1. Due to the simple reporting process, it only takes a few hours for } \\
\text { health workers to fully grasp the reporting process. } \\
\text { 2. MESSID can adapt to changing information needs if necessary. } \\
\text { 3. MESSID can flexibly change the content of the questionnaire if } \\
\text { necessary. }\end{array}$ \\
\hline $\begin{array}{l}\text { Highly } \\
\text { efficient }\end{array}$ & $\begin{array}{l}\text { 1. Limited information was analyzed and reported. } \\
\text { 2. Difficulty for real-time surveillance and risk } \\
\text { assessment of outbreaks of infectious diseases. }\end{array}$ & $\begin{array}{l}\text { 1. Real-time integration and analysis of demographical, } \\
\text { spatiotemporal, clinical, epidemiological, therapeutic, and laboratory } \\
\text { testing information. } \\
\text { 2. Easy for real-time surveillance and risk assessment of outbreaks of } \\
\text { infectious diseases. }\end{array}$ \\
\hline Acceptability & $\begin{array}{l}\text { 1. More additional work in the data input, collection, } \\
\text { and analysis. } \\
\text { 2. More additional work on the draft of disease report. }\end{array}$ & $\begin{array}{l}\text { 1. Almost no additional work in the data collection, analysis. } \\
\text { 2. Automatically generate reports on demand. }\end{array}$ \\
\hline
\end{tabular}

Abbreviations: MESSID=mobile electronic surveillance system for infectious diseases; SMS=short message service. 
Global Public Health Intelligence Network and HealthMap, which are used to collect case or outbreak data, manage case databases, and analyze data thereby promoting the prevention, monitoring, and control of infectious diseases (8). These information systems mainly rely on big data technologies to capture information related to infectious diseases on the Internet to display the status of global emerging or reemerging infectious diseases and provide early warnings for potential disease outbreaks by data integration, analysis, and risk assessment (9). However, this is not suitable for developing countries with the lack of fundamental disease surveillance system based on case information. In addition, building an infectious disease electronic surveillance system requires not only network data transmission capabilities, but a practical infectious disease surveillance framework. MESSID is not only an infectious disease monitoring software, but more importantly, it provides a ready-to-use real-time mobile monitoring solution for infectious diseases in developing countries without electronic reporting tools of infectious diseases, MESSID is a software system independently developed by the Beijing Institute of Microbiology and Epidemiology, which has all intellectual property rights and provides authorization or permission to use. No costly software is required for the installation of the MESSID, which has system-level security to protect key data by using data transmission and storage encryption technology that is helpful for its wide application in other developing countries. In addition, support from authorities has been the most important factor in the successful implementation and operation of MESSID. The system has also enabled group coordination and information sharing among the various entities so decision makers can obtain data in time and transfer information with health officials (10-11).

One of the obstacles to efficient implementation of the MESSID in its current form lies in the low capacity of laboratory diagnosis in Sierra Leone, and the probable misdiagnosis of diseases. These limitations might undermine the reliability and accuracy of data submitted to MESSID. The poor infrastructure and the cost to implement MESSID might also deter efforts of nationwide implementation. Still, it is helpful for some developing countries to establish information systems to meet their particular needs of infectious disease surveillance from this study.

Funding: The China Mega-Project on Infectious Disease Prevention (2018ZX10101003-002), the Key
Research and Development Program of China (2019YFC1200604), and the National Natural Science Funds (81825019).

doi: $10.46234 / \mathrm{ccdcw} 2021.189$

\# Corresponding authors: Yajun Song, songyajun88@aliyun.com; Wei Liu, liuwei@bmi.ac.cn; Liqun Fang, fang_lq@163.com; Yansong Sun, sunys1964@hotmail.com.

\begin{abstract}
${ }^{1}$ State Key Laboratory of Pathogen and Biosecurity, Beijing Institute of Microbiology and Epidemiology, Beijing, China; ${ }^{2}$ College of Life Science and Technology, Beijing University of Chemical Technology, Beijing, China; ${ }^{3}$ College of Medicine and Allied Health Sciences, University of Sierra Leone, Freetown, Sierra Leone; ${ }^{4} 34$ Military Hospital, Wilberforce, Freetown, Sierra Leone.

\& Joint first authors.
\end{abstract}

Submitted: July 19, 2021; Accepted: August 18, 2021

\section{REFERENCES}

1. Chan EH, Brewer TF, Madoff LC, Pollack MP, Sonricker AL, Keller $\mathrm{M}$, et al. Global capacity for emerging infectious disease detection. Proc Natl Acad Sci USA 2010;107(50):21701 - 6. http://dx.doi.org/10. 1073/pnas.1006219107.

2. Dowell SF, Tappero JW, Frieden TR. Public health in Haitichallenges and progress. N Engl J Med 2011;364(4):300-1. http://dx.doi.org/10.1056/NEJMp1100118.

3. Perry HN, McDonnell SM, Alemu W, Nsubuga P, Chungong S, Otten MW Jr, et al. Planning an integrated disease surveillance and response system: a matrix of skills and activities. BMC Med 2007;5:24. http://dx.doi.org/10.1186/1741-7015-5-24.

4. World Health Organization. WHO welcomes Chinese contribution of mobile laboratory and health experts for Ebola response in West Africa. 2015. https://www.afro.who.int/media-centre/statements-comment aries/who-welcomes-chinese-contribution-mobile-laboratory-andhealth. [2015-4-5].

5. World Health Organization. Sierra leone. 2021. https://www.who. int/countries/sle/. [2021-8-17].

6. Baloyi RE, Shandukani MB, Graffy R, Misiani E, Mayet N, Mabunda E, et al. Evaluating a 24-h mobile reporting system for malaria notifications in comparison with a paper-based system in South Africa, 2015. Malar J 2018;17(1):308. http://dx.doi.org/10.1186/s12936-0182451-x.

7. World Health Organization. Statement on the second meeting of the International Health Regulations (2005) Emergency Committee regarding the outbreak of novel coronavirus (2019-nCoV). 2020 https://www.who.int/news/item/30-01-2020-statement-on-the-secondmeeting-of-the-international-health-regulations-(2005)-emergencycommittee-regarding-the-outbreak-of-novel-coronavirus-(2019-ncov). [2020-1-31].

8. Chanlekha H, Kawazoe A, Collier N. A framework for enhancing spatial and temporal granularity in report-based health surveillance systems. BMC Med Inform Decis Mak 2010;10:1. http://dx.doi.org/ 10.1186/1472-6947-10-1

9. Madoff LC, Li AN. Web-based surveillance systems for human, animal, and plant diseases. Microbiol Spectr 2014;2(1):OH-0015-2012. http://dx.doi.org/10.1128/microbiolspec.OH-0015-2012.

10. Lin YB, Heffernan C. Accessible and inexpensive tools for global HPAI surveillance: a mobile-phone based system. Prev Vet Med 2011;98(2 3):209 - 14. http://dx.doi.org/10.1016/j.prevetmed.2010.10.003.

11. Robertson C, Sawford K, Daniel SLA, Nelson TA, Stephen C. Mobile phone-based infectious disease surveillance system, Sri Lanka. Emerg Infect Dis 2010;16(10):1524 - 31. http://dx.doi.org/10.3201/eid1610. 100249 . 